\title{
Social Pedagogy Photo Essay - A Picture Says More Than a Thousand Words
}

Gabriel Eichsteller ${ }^{1, *}$

How to cite: Eichsteller, G. 'Social Pedagogy Photo Essay - A Picture Says More Than a Thousand Words.' International Journal of Social Pedagogy, 2017, 6 (1), pp.83-88. DOI: https://doi.org/10.14324/111.444.ijsp.2017.v6.1.006

Published: 6 October, 2017

\section{Copyright:}

(C) 2017, The Author(s) - This is an Open Access article distributed under the terms of the Creative Commons Attribution License (CC-BY) 4.0 https://creativecommons.org/licenses/by/4.0/, which permits unrestricted use, distribution and reproduction in any medium, provided the original author and source are credited • DOI: https://doi.org/10.14324/111.444.ijsp.2017.v6.1.006

\section{Open Access:}

International Journal of Social Pedagogy is a peer-reviewed open access journal. 


\title{
Social Pedagogy Photo Essay - A Picture Says More Than a Thousand Words
}

\author{
Gabriel Eichsteller
}

Explaining social pedagogy to anyone who has never heard the term before can be a tricky task and is limited if all that can be used to convey its meaning is words. That's one of the reasons why we invited contributions to a photo competition and involved the social pedagogy community on Facebook to select a new cover image for the re-branded International Journal of Social Pedagogy. Below are the top five entries, with short explanations from the contributors themselves. Thanks to everyone who submitted a photo and to all who cast their votes. We're always interested in new photos, which you can send to: editors@internationaljournalofsocialpedagogy.com.

The winning photo came from the University of Central Lancashire, who have recently developed both modules and a brand new Bachelor's degree in social pedagogy. The module is taught in a blended learning style, with an emphasis on experiential learning, critical reflection and

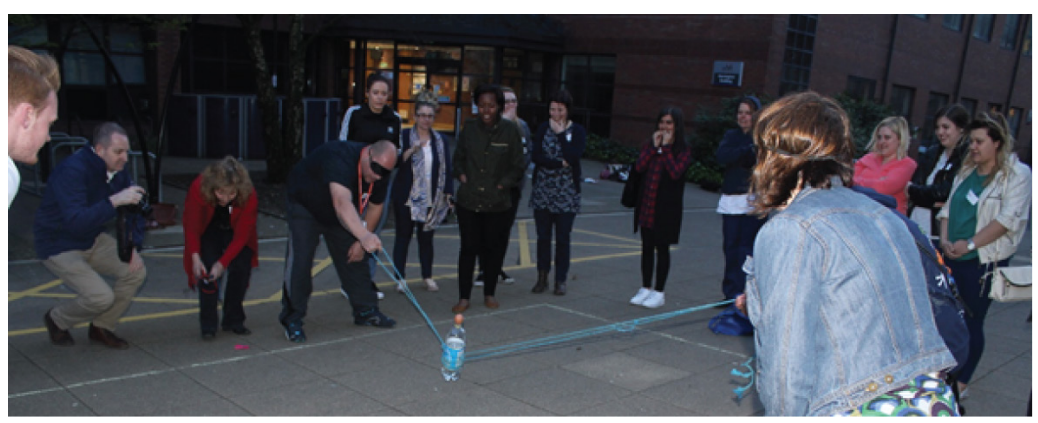

Winning photo: University of Central Lancashire (Source: Jane Lloyd). Distributed under a CC BY license (CC-BY) 4.0 https://creativecommons.org/licenses/by/4.0/. 
creative activities to help students embed their learning in practice. As one of the students involved in the group activity pictured below explains:

There's nothing better than going to university walking into a lecture and having the best laugh meeting amazing people and discovering Social Pedagogy, which shows you can work in a positive way. Being able to put a name to the way I work with young people was exciting and has meant that I can pass that on to colleagues and friends, and it has strengthened my practice.

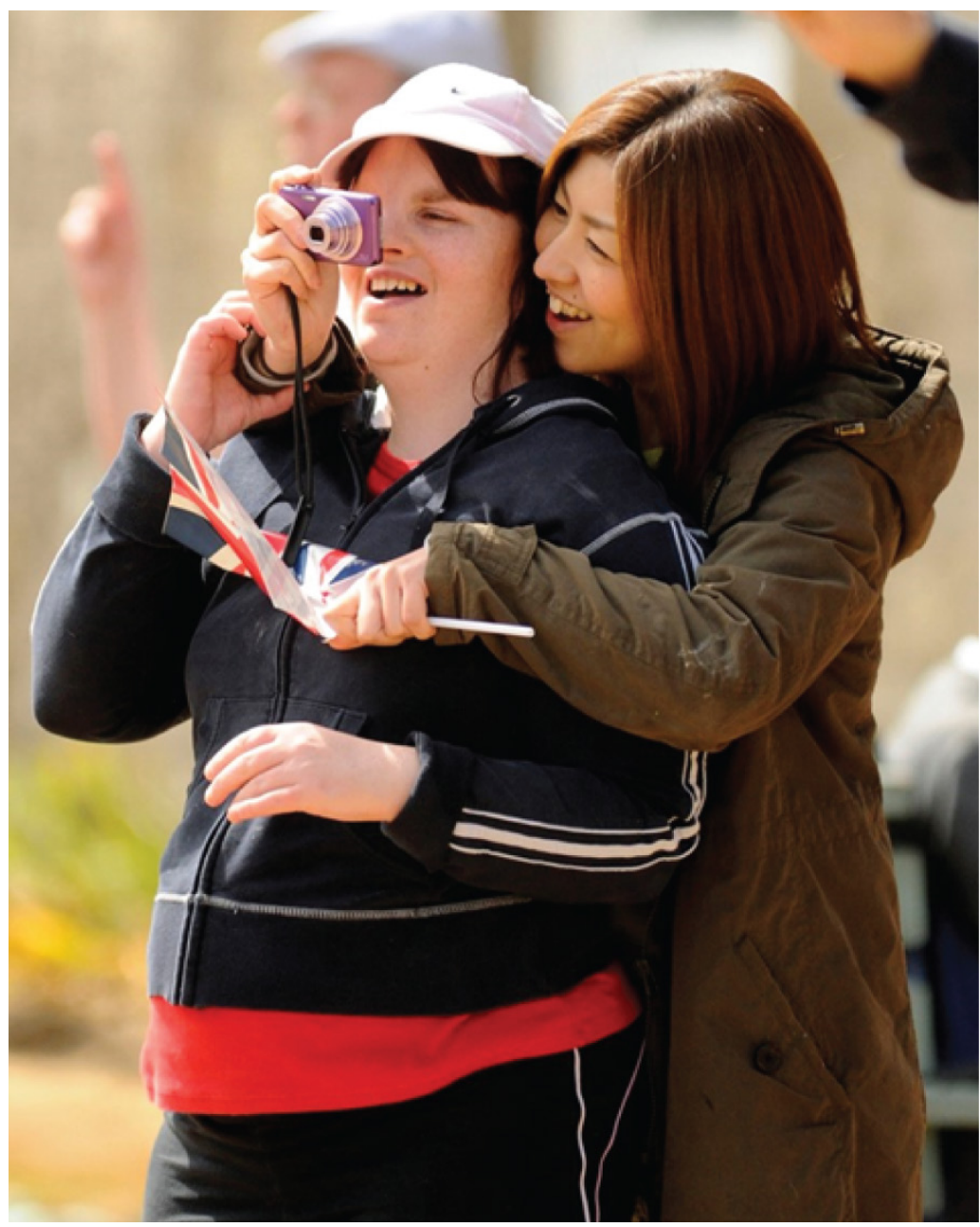

Runner-up: Camphill Community Blair Drummond (Source: Jocelyn Glebocki). Distributed under a CC BY license (CC-BY) 4.0 https://creativecommons.org/licenses/ by $/ 4.0 /$. 
While the photo attracted the most likes on Facebook, thanks to UCLAN's collective social media power, the panorama format of the image unfortunately didn't lend itself to the new journal cover.

In joint second place was this photo submitted by the Camphill Community in Blair Drummond, Scotland, who were part of a Scottish Government funded pilot scheme in 2014 (see Roesch-Marsh et al., 2015). We agreed with Facebook voters that this image would make a great journal cover conveying many important aspects of social pedagogy.

Here we see Leanne and her co-worker working together to take a photograph. Using the principles of Social Pedagogy, the co-worker and Leanne have chosen an activity which they both enjoy and can work on together (the Common Third). In participating in a shared activity, they are building and strengthening their own relationship. The experience is a positive one, it is fun, enjoyable and brings Leanne a sense of happiness and well-being. Through the support provided by the co-worker, Leanne can choose her subject matter and take control of the activity session. Consequently she is empowered and has the opportunity to learn. The Diamond Model in practice!

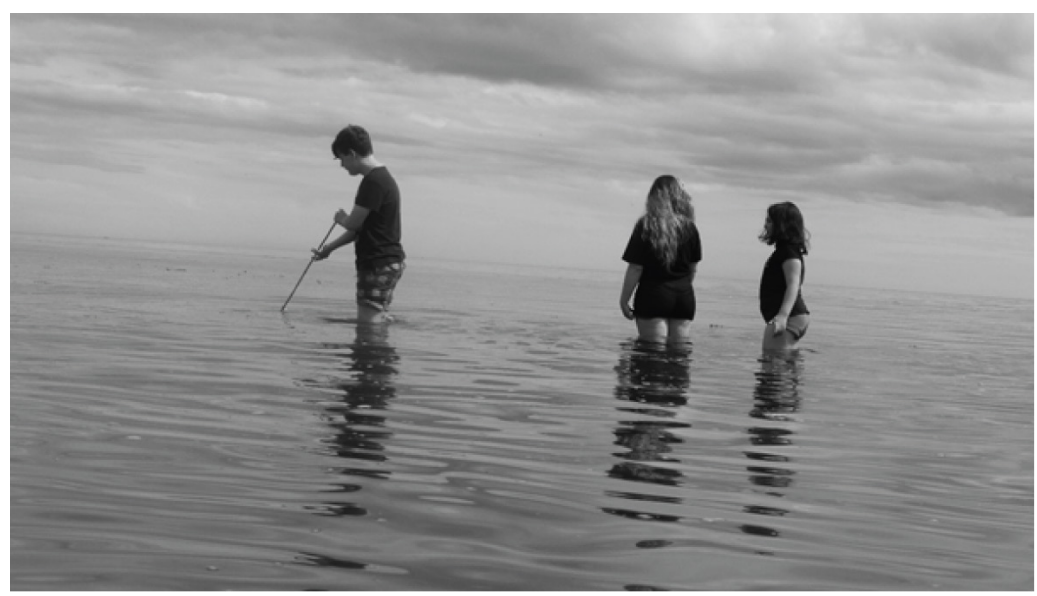

Runner-up: Debra Dawkins (Source: Debra Dawkins). Distributed under a CC BY license (CC-BY) 4.0 https://creativecommons.org/licenses/by/4.0/.

This great photo submitted by Debra Dawkins shared second place. As Debra explains: 
The photo was taken in the North Sea at Robin Hoods Bay. To me it was hard to let them wade out (they were much further out after this) not knowing what was in the water and how they would cope if Scarlett fell over (she has anxiety disorder) or they found something, but they all share a love of the seaside. I wasn't in a position to help immediately (I was quite a long way off on the beach), but they helped each other, worked out ways of walking in the water against the tide and kept each other within sight and discovered all sorts about the sea and themselves. I let them find their own way of completing the task, supporting each other assessing the risks (as was I) without it interfering in their fun. They owned the experience - it was all theirs, they planned it, led it and completed it their way.

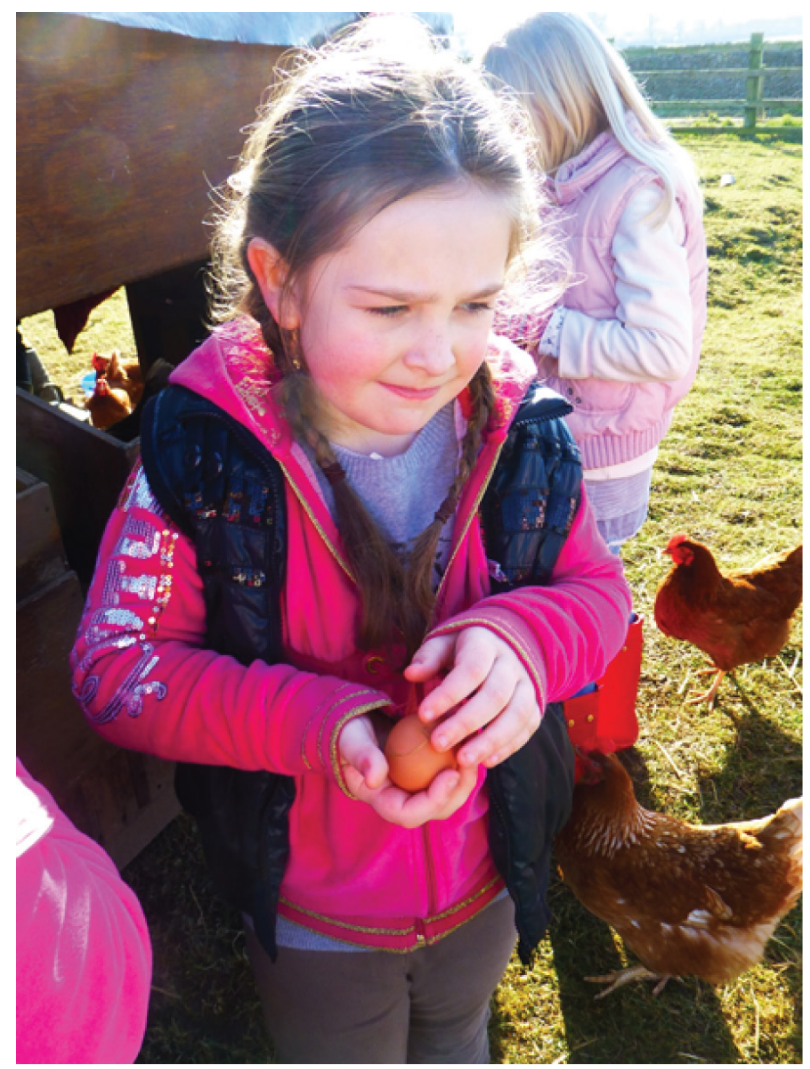

Fourth place: Debra Dawkins (Source: Debra Dawkins). Distributed under a CC BY license (CC-BY) 4.0 https://creativecommons.org/licenses/by/4.0/. 
Debra's other photo submission landed in fourth place. She described how learning about social pedagogy has impacted on her parenting:

My daughter is animal mad and wanted to spend her birthday at a farm. She milked cows, mucked out the donkeys, fed the sheep, but the best bit was gathering the eggs from the chickens. She is interested in where food comes from and what you do with it. We bought the eggs so she could take them home and she made a cake with them, which she shared with everyone. It was a fun day, but the science lesson, the skill building and the confidence she gained from it were a huge part of the day too - and the best part was seeing her sense of achievement. I stand back more as a parent, I let them take more charge of activities, and I see them grow before my eyes.

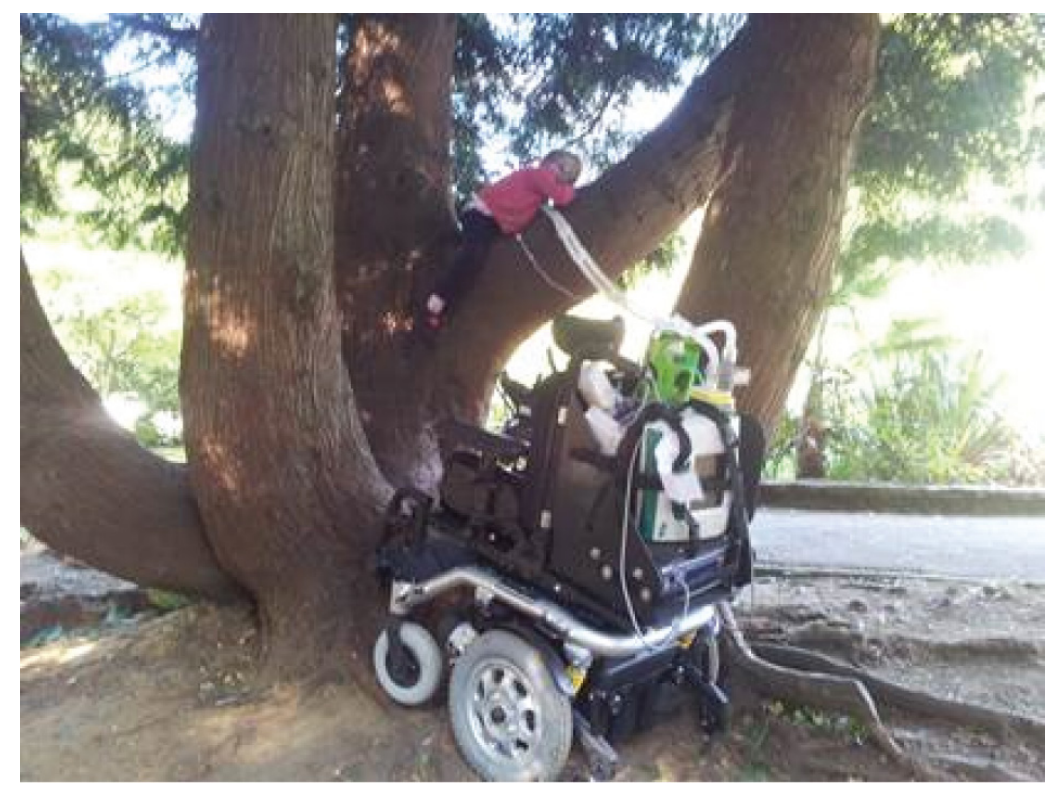

Fifth Place: John Palczynski (Source: John Palczynski). Distributed under a CC BY license (CC-BY) 4.0 https://creativecommons.org/licenses/by/4.0/.

John, a foster carer with Surrey County Council who took part in the Head, Heart, Hands demonstration programme (McDermid et al., 2016), submitted this photo picturing his foster daughter Summer with her wheelchair parked right up a tree so that she could lie on a branch. He explains the story behind this: 
We often watch The Sound of Music for the songs! Spotting children in trees, I realised my social pedagogical blind spot for Summer's potential: She has never climbed a tree. I earmarked that thought. Months later, at a picnic, a child played on a tree and the thought came alive in me again. Summer said roots were in the way, and I detected an appeal to stop. Our relationship let me reveal that I would be her 'scaffolding' while she needed it. Factually, the roots were a struggle, but we did it together. Comfortable on the lowest branch, I had to keep Summer's panic zone away and encourage her to enter her learning zone by helping her up higher, knowing our trust. When she wanted to get down, I offered the idea of 'want a photo?' - 'Yes'!

\section{References}

McDermid, S., Holmes, L., Ghate, D., Trivedi, H., Blackmore, J., \& Baker, C. (2016). The Evaluation of Head, Heart, Hands - Introducing Social Pedagogy into UK Foster Care. Final synthesis report. Loughborough: Centre for Child and Family Research. http://www.lboro.ac.uk/media/www lboroacuk/content/ccfr/publications/HHH\%20evaluation\%20full\%20 report\%20FINAL.pdf?mc_cid $=645$ ece6da8\&mc_eid $=$ d75dc6ed38

Roesch-Marsh, A., Cooper, S., \& Kirkwood, S. (2015). Social Pedagogy Pilot Project Evaluation. Edinburgh: University of Edinburgh. http://www. camphillscotland.org.uk/media/66289/camphill_final_version.pdf 